\title{
The Impact of a Local Development Project on Social Capital: Evidence from the Bohol Irrigation Scheme in the Philippines
}

\author{
Hogeun Park ${ }^{1,2}$, Takuji W. Tsusaka ${ }^{3}$, Valerien O. Pede ${ }^{4}$ and Kyung-Min Kim ${ }^{5, *}$ \\ 1 School of Planning, Design, and Construction, Michigan State University, 202 Manly Miles Building, \\ 1405 S. Harrison Road, East Lansing, MI 48823, USA; parkhoge@msu.edu \\ 2 Center for Global Change and Earth Observation (CGCEO), Michigan State University, \\ 202 Manly Miles Building, 1405 S. Harrison Road, East Lansing, MI 48823, USA \\ 3 International Crops Research Institute for the Semi-Arid Tropics (ICRISAT), Chitedze Agricultural Research \\ Station, P.O. Box 1096, Lilongwe, Malawi; takuji.tsusaka@gmail.com \\ 4 International Rice Research Institute (IRRI), DAPO Box 7777, Metro Manila 1301, Philippines; v.pede@irri.org \\ 5 Graduate School of Environmental Studies, Seoul National University, \#82, 1 Gwanak-ro, Gwanak-gu, \\ Seoul 08826, Korea \\ * Correspondence: kkim2@snu.ac.kr
}

Academic Editor: Davide Viaggi

Received: 5 December 2016; Accepted: 7 March 2017; Published: 10 March 2017

\begin{abstract}
The purpose of this paper is to investigate the connection between local development projects and the residents' social capital in Bohol, The Philippines. From this perspective, we hypothesized that social behaviors of local farmers are influenced by the availability of canal irrigation due to the collective water management required in irrigated societies. By combining the results of the ultimatum game (UG) with a household survey on 245 villagers in Bohol, this paper (1) measures the degree of social capital at the individual level and (2) quantifies the effects of irrigation on social capital by controlling household as well as individual characteristics. Moreover, we employed a Spatial Autoregressive model to explore the spatial effects and social contexts of farmers' behavioral patterns. The empirical results show that the level of measured social behavior is strongly associated with access to community irrigation water and asset holdings. Additionally, increased physical distance between residents leads to a decrease in social capital, or interdependency, among them. The results suggest that community engagement (e.g., irrigation management committee and turnout service association) with local development projects would not only improve agricultural productivity but also enhance social relationships among farmers, highlighting its importance.
\end{abstract}

Keywords: local development; behavioral experiment; spatial autoregressive model; social capital; community engagement; ultimatum game

\section{Introduction}

Over the past 50 years, Official Development Assistance (ODA)—international aid for economic development and welfare provided by multinational agencies [1] - has been continuously implemented in developing countries. In particular, during the 1970s, international aid agencies and donor countries recognized the dangers of unbalanced economic development in developing countries and began employing local development projects, which aimed to improve the livelihoods of those suffering from economic and societal difficulties in selected areas. Considering that nearly 1.2 billion people and $75 \%$ of the destitute poor work in agriculture, forestry, and fisheries across the globe [2], local development projects associated with the primary sector of the recipient can be efficient policy making tools to enhance these living conditions [3]. Many studies have focused on the impact assessment of 
ODA projects regarding aid effectiveness. Despite the rising number of impact assessments, only a few have empirically addressed the social impacts of these projects on residents [4]. Even so, for the past several decades, many researchers and activists have realized significant social changes by local development projects through participation and cooperative activities [5].

We employed the concept of social capital to scrutinize the social impact and changes brought forth by local development projects. The early definition of social capital is discussed by Putnam [6] and Coleman [7]. Putnam [5] defined social capital as features of a social organization that facilitate mutual benefits. Coleman [6] described social capital as an informal social network among stakeholders pursuing their economic benefits within close social bonds. Later, a large volume of literature discussed the close linkages between local economic development and social capital (i.e., effective cooperation through people's voluntary behaviors and co-operative interaction) [6-11]. In particular, Bowles and Gintis [10] attempted to argue that social capital (e.g., social norms, trust, and punishment among people belonging to communities or groups) is a means to solve market failure in a capitalist society.

While social capital analysis is meaningful for assessing the social impact of local development projects, quantitative evidence of how social capital is related to local development is relatively scarce. The lack of evidence owes to the broad definition of social capital, which leads to difficulty in quantitatively measuring its value. In response to these limitations, various scholars have attempted to use several innovative methods. Particularly, in development studies, Baud et al. [12] implemented a percentage of socially disadvantaged groups in a sample population to indicate the deprivation of social capital. Mitra [13] used urban immigrants' residence period as social capital to verify the relationship between social capital and the informal job network. More so, Baud et al. [11] and Mitra [12] attempted to capture social capital within neighborhoods (i.e., communities sharing similar geographical and/or social environment), leaving room for a more rigorous quantitative analysis of social capital. To add further perspective, we propose measuring social capital to reveal its relationship to an irrigation project and its beneficiaries. In light of the importance of public participation in local development projects [14,15], it is essential to quantify the social capital of the beneficiaries to understand the social impact of the irrigation project.

A relatively large number of studies have investigated social capital in regards to irrigation schemes [16-18]. Since water management and regulation is vital to enhancing productivity on agricultural lands, much research has focused on the importance of structural social capital-i.e., social norms and regulation in irrigation management $[16,17]$. However, while social capital can be measured and implemented in diverse perspectives, such as institutional $[19,20]$ and transplanted community structures [17,21], many studies have focused on how social capital impacts irrigation schemes rather than vice versa. Hence, research focusing on the accumulation of social capital under an irrigation scheme at the stakeholder level is scarce [16]. Empirical evidence is required to fully understand the impact of an irrigation scheme on the formation of social capital. In this study, we employ a behavioral experiment to explore this empirical evidence.

Behavioral experiments, which have been developed by behavioral economists since 1960, are key instruments to measure social capital in this study. In the early stages of behavioral economics, researchers did not pay attention to the anomalies and the meanings of the players' payoff; rather, they assumed that players aimed to maximize their benefits and minimize their costs out of self-interest [22]. Follow-up experiments, however, revealed that anomalies were related to the players' perception of fairness [23]; that is, a player's consideration of fairness and retaliation under the various institutional environments shape their behavior [24]. Given this context, game theory and behavioral experiments have been employed by several scholars [24-28] to measure social capital. In summary, these studies have revealed that the self-interest model failed to confirm the assumption of individual selfishness [24]. In particular, players exhibit more altruistic behavior toward a known rather than an unknown counterpart [26], meaning that people who have strong relations within neighborhoods exhibit pro-social behavior to a greater extent. 
Our research is intended to quantitatively examine whether and to what extent the execution of collective common resource management affects the farmers' behavioral patterns. Within our study site in the Philippines, the Bayongan irrigation system, an irrigation canal, was constructed under the support by the Japan International Cooperation Agency (JICA) in 2008. Prior to construction, the irrigated and non-irrigated (rainfed) areas were adjacent and had shared the same cultural, agroecological, and economic environments. Due to an unexpected funding shortage, irrigation was not introduced into the rainfed areas during the project period. Therefore, the irrigation scheme can be treated as a random (non-selective) and an exogenous intervention experiment. In addition to experimental irrigation, our study incorporates a unique blend of two notable features. First, we employ a behavioral experiment known as an ultimatum game (UG), which enables us to quantify the farmers' social capital. Second, we employ spatial econometrics to control for the spatial spillover of social capital among neighboring farmers; this process is essential when addressing the possible estimation bias that arises from not modeling the spillover [23]. Additionally, our interpretation of statistical results was supported by semi-structured interviews of selected residents, which illuminates the local context of societal changes contingent to the irrigation scheme. With these methodologies, we hypothesized that: (1) farmers have different levels of social capital; and that (2) community engagement activities, when linked to the collective management of an irrigation system, would foster the farmers' pro-social behaviors.

\section{Materials and Methods}

\subsection{Study Area}

Our target area lies in Bohol Province in the central region of the Philippines (Figure 1). The study focuses on the Bayongan Irrigation System, located in the northeastern part of Bohol Island (about $50 \mathrm{~km}$ from the provincial capital city of Tagbilaran), which began operation in May 2008. The total service area covers approximately 3295 ha of agricultural land. The total lengths of the main canal, sub-canals, and sub-lateral canals are $17.5 \mathrm{~km}, 32.9 \mathrm{~km}$ and $6309 \mathrm{~km}$, respectively. The irrigation canals span three municipalities-San Miguel, Trinidad, and Ubay—which are divided into 18 barangays. A barangay is the smallest administrative division in the Philippines, which is the subdivision of municipality. The Bayongan local development projects planned and granted by JICA financially supported this irrigation system. Unlike previous irrigation projects in the Philippines, the concrete canals with metal-based water gates are able to prevent water leakage and random water abuse by farmers. As discussed in the introduction, our sample farmers were chosen from both irrigated and non-irrigated areas. Thus, our analysis employs the data on beneficiaries (farmers with irrigated farmlands) and non-beneficiaries (farmers with rainfed farm lands).

As a way to effectively manage the collective use of the irrigation canals in the Bayongan Irrigation Scheme, the National Irrigation Administration (NIA) formed multiple Irrigation Associations (IA) and Turnout Service Areas (TSA) across the region that were established based on each lateral service area (Figure 2). The IA committees consist of TSA leaders who use the irrigation scheme. Monthly meetings facilitate communication among TSA leaders in regard to system maintenance and scheduled water usage. Each TSA consists of about twenty farmers, whose responsibilities include management, organization, and scheduling of water rotation among the fields within the group. This TSA structure keeps farmers accountable to each other. 


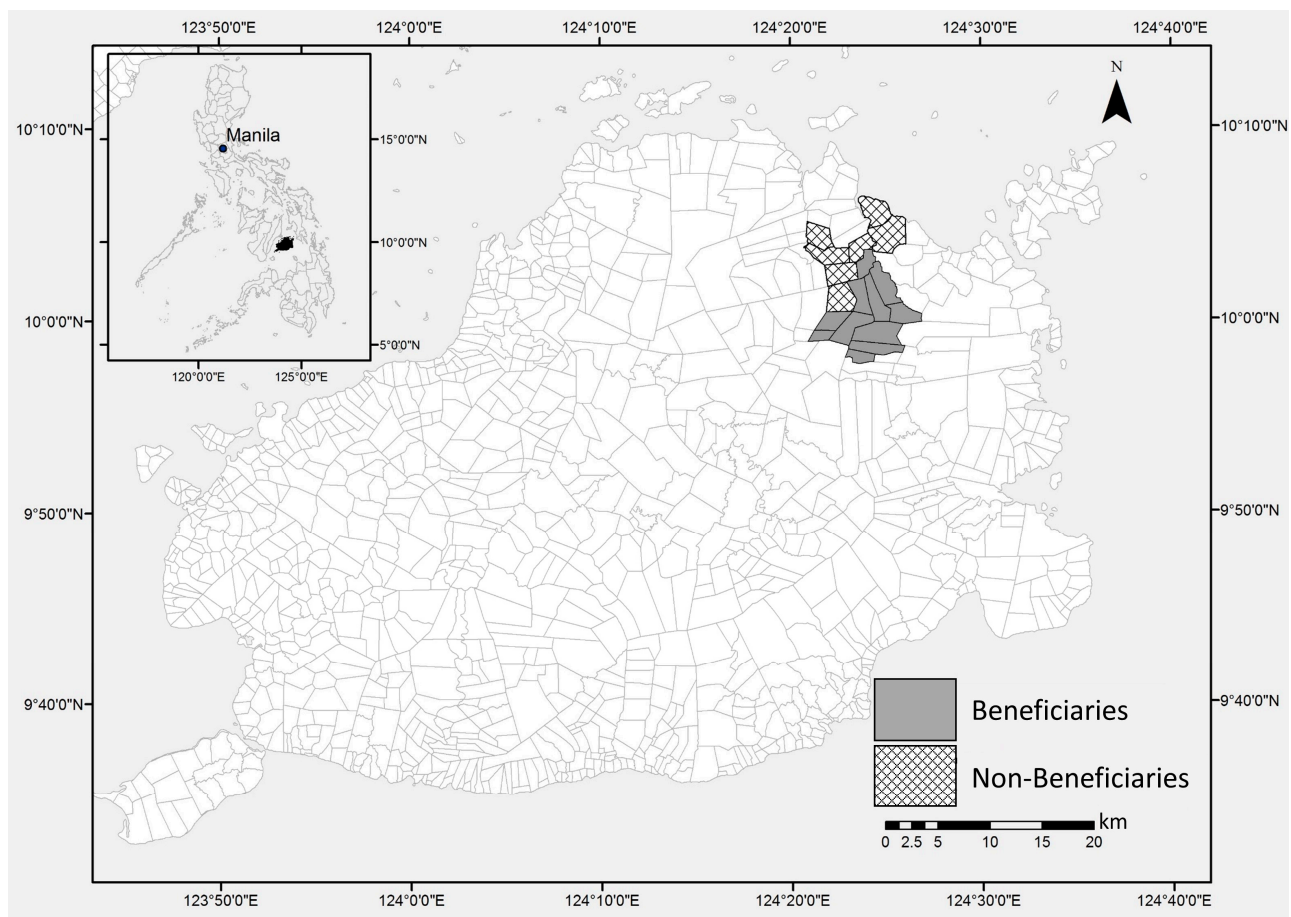

Figure 1. Study sites in Bohol province, the Philippines.

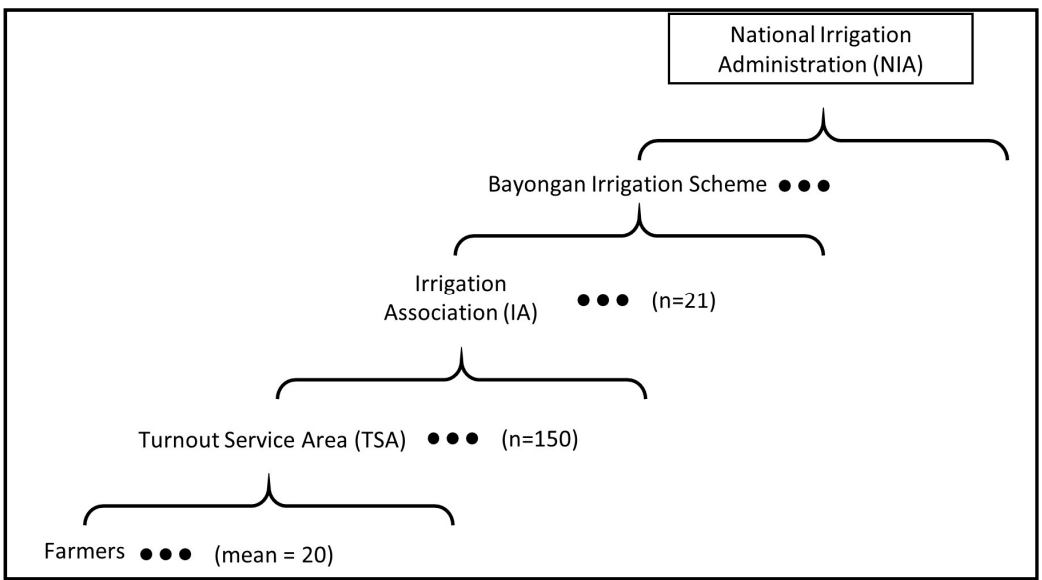

Figure 2. Organizational structure of National Irrigation Administration (NIA), Irrigation Associations (IA) and Turnout Service Areas (TSA).

\subsection{Experimental Design}

The three empirical tools employed in this study include: (1) a behavioral experiment; (2) semi-structured interviews; and (3) a spatial autoregressive (SAR) model. Since we aim to highlight the benefits of game experiments and SAR modeling when analyzing data that are likely to be spatially correlated, the semi-structured interview would be used as an auxiliary material.

\subsubsection{Behavioral Experiments}

Behavioral experiments are designed to quantify the participants' social behavior under strategic situations [29]. Among a range of games to select, this study chose the ultimatum game (UG), which was developed to elicit the behavioral levels of tolerance or retaliation. We ran six-day workshops at the study sites to conduct UG in the National Irrigation Administration regional office and in community halls in August 2011. We collected results from 131 beneficiaries and 114 non-beneficiaries. 
The experiments were conducted alongside local staff from the International Rice Research Institute (IRRI) in English and Cebuano and were supervised by the IRRI Social Sciences Division (SSD). While IRRI did not have an institutional review board during the study period, this work was reviewed and approved through an internal review process by the head of the SSD. In addition, to meet an ethical standard, we conducted experiments with only volunteer participants. All participants were provided instructions prior to their participation and had the option to terminate the experiment at any point. In addition, the enumerators sought and proceeded only upon consent at the beginning of each interview. The Chief Information Officer of IRRI approved these procedures.

Participants required for an UG experiment to include a sender and receiver, both of who should be anonymous. Given a certain endowment of money (i.e., 100 Philippine pesos (PhP) in this experiment), the sender decides whether to transfer a discretionary amount to the receiver, who has the option to accept or reject the transfer. Before the sender decides how much to transfer, the receiver sets a minimum threshold that determines whether they will accept the monetary offer. If the monetary offer is equal to or greater than the threshold, the receiver accepts the transfer and the transferred amount becomes the receiver's payoff. The remaining amount (i.e., equal to $100 \mathrm{PhP}$ minus the offer) becomes the sender's payoff. However, if the transfer is rejected due to not reaching the threshold set by the receiver, then both the sender and receiver end up with zero payoff. We recorded the threshold value set by each receiver as an UG result. According to the rational choice theory $[9,29]$, the optimal strategy for the receiver is to accept any amount of transfer (i.e., the threshold being zero PhP). However, in the real world, a receiver often sets a relatively high threshold that reflects behavioral levels of retaliation. In an experiment by Sanfey et al. [30], over 50\% of the receivers set the threshold below $20 \%$ of the total endowment senders could offer. In addition, $62 \%$ of the senders sent more than $20 \%$ of the endowment in the experiment by Hoffman et al. [27]. These results show that participants consider fair distribution. Thus, the game can capture levels of altruism and retaliation among participants. One the one hand, greater threshold values indicate a higher tendency to retaliate for an unfair distribution. On the other hand, the smaller threshold values indicate a higher willingness to tolerate the level of distribution. Therefore, the recorded threshold of the receiver is considered an indicator of retaliation and tolerance level [29]. An alternative interpretation is that the threshold values are an indicator of fairness up to a certain level of threshold [23]. In our model, we included the receivers' threshold of the UG exercise as the dependent variable in a Spatial Autoregressive (SAR) model.

\subsubsection{Collecting Socio-Economic Household Data}

The IRRI collected agricultural and socioeconomic variables using household surveys conducted from 2009 to 2010. Based on this data set, we matched socio-economic and agricultural data from 131 beneficiaries and 114 non-beneficiaries in the study area who participated in behavioral experiments. We included socio-economic as well as household characteristic variables in our model—such as age, schooling years, asset holdings, household size, gender and female ratio-to account for the effects of these factors, as these variables are often associated with degree of social capital [31-33] and are found to critically determine the cooperation scale in the previous literature $[31,34,35]$. While Berg et al. [26] proposes the consideration of ethnic heterogeneity in villages, we chose not to include ethnicity, language, and religion because those are nearly homogenous in our study site. Since it is vital to incorporate the geographical location of farmers to understand their social capital, we also compiled the GPS locations of households to the data set. The average distance between neighboring farmers was $2.48 \mathrm{~km}$, with a standard deviation of $1.94 \mathrm{~km}$. The distance from a farmer to a neighboring farmer among the beneficiaries (mean $=2.78 \mathrm{~km}$ ) and among the non-beneficiaries (mean $=2.24 \mathrm{~km}$ ) was statistically significantly different according to the $t$-test $(p<0.05)$.

Table 1 presents descriptive statistics for the demographic variables. The respondents were mainly head of the household, male, and were, on average, approximately 51 years old. Average schooling years was equivalent to the time needed to complete elementary school according to the Philippine education system. 
Table 1. Descriptive statistics of the respondents' demographic information for non-beneficiaries and beneficiaries.

\begin{tabular}{ccccccc}
\hline Respondents & $\begin{array}{c}\text { Number of } \\
\text { Observations }\end{array}$ & $\begin{array}{c}\text { Average Age } \\
\text { (Std. Dev) }\end{array}$ & $\begin{array}{c}\text { Average Schooling } \\
\text { Years (Std. Dev) }\end{array}$ & $\begin{array}{c}\text { \% of Female } \\
\text { Participants }\end{array}$ & $\begin{array}{c}\text { Marriage } \\
\text { Rate (\%) }\end{array}$ & $\begin{array}{c}\text { Literacy } \\
\text { Rate (\%) }\end{array}$ \\
\hline Total & 245 & $51.2(12.2)$ & $6.3(3.0)$ & 29.0 & 91 & 98 \\
Non-beneficiaries & 114 & $53.0(11.9)$ & $6.6(3.2)$ & 34.2 & 89 & 96 \\
Beneficiaries & 131 & $49.6(12.2)$ & $6.1(2.9)$ & 24.4 & 91 & 100 \\
\hline
\end{tabular}

The beneficiaries and non-beneficiaries of the irrigation scheme do not have significant differences in their demographic statistics. Based on the independent sample $t$-test, no significant differences in marital status $(p=0.571)$, education level $(p=0.155)$, or gender ratio $(p=0.093)$ were found at the $5 \%$ statistical significance level. Even though age $(p=0.032)$ differed statistically between the two groups, the magnitude of the difference was not large (1.8 years). It is not surprising that the two groups were similar, since the two study areas were adjacent to each other, and the selection into the irrigation scheme was at random. Furthermore, our interviews confirmed that the irrigation system project had not caused existing residents to relocate until the time of the experiment, and that the basic demographic status had not changed after the irrigation project.

Household-level characteristics showed small differences between the beneficiaries and non-beneficiaries, except for asset holdings (Table 2). The non-beneficiaries had larger assets than the beneficiaries. We checked income sources and found that, for the beneficiaries, $56 \%$ of the income came from agriculture while $34 \%$ of income for the non-beneficiaries relied on agriculture. According to the semi-structured interviews, off-farm income sources were from short-term businesses and daily piecework. It may be the case that the irrigation beneficiaries began to reduce their engagement in off-farm activities as a result of increased reliability in agricultural production and reallocated their assets into consumption and investment activities. Examining the correlation between the control variables, none of the correlation coefficients exceeded 0.35 in absolute terms, leading us to assume that there was no high multicollinearity in our regressions. A negative correlation was found between age and schooling years, reflecting the fact that the public education program was in the process of improvement during the study period.

Table 2. Family composition and assets of the sampled households for non-beneficiaries and beneficiaries.

\begin{tabular}{ccccc}
\hline Respondents & $\begin{array}{c}\text { Number of } \\
\text { Observations }\end{array}$ & $\begin{array}{c}\text { Average Number of Household } \\
\text { Members (Std. Dev) }\end{array}$ & $\begin{array}{c}\text { Average Female } \\
\text { Ratio (Std. Dev) }\end{array}$ & $\begin{array}{c}\text { Average Asset } \\
\text { Holding (PhP) }\end{array}$ \\
\hline Total & 245 & $5.9(2.3)$ & $0.5(0.2)$ & 63,775 \\
Non-beneficiaries & 114 & $5.7(2.3)$ & $0.5(0.2)$ & 71,145 \\
Beneficiaries & 131 & $6.2(2.3)$ & $0.5(0.1)$ & 56,613 \\
\hline
\end{tabular}

Note: The exchange rate was USD $1=\mathrm{PhP} 43.7$ as of 2010.

\subsubsection{Semi-Structured Interviews}

To understand the local context of social behavior, our research group conducted semi-structured interviews during two site visits, once in December 2012 and another in March 2013. We interviewed eight farmers during each visit. These semi-structured interviews were intended to understand the residents' involvement in the irrigation project, including: (1) planning; (2) construction; and (3) management. We conducted interviews with local staff of IRRI. The trained research team also contacted residents with TSA leaders and asked the following questions: (1) Are there any conflicts with the planning, construction, and management of the irrigation scheme; (2) what is the major role of TSA; and (3) are there any special programs in TSA groups to join other than participating in scheduled irrigation? By using these questions as a framework, we conducted 10-15 min semi-structured interviews. These interviews were recorded and participants remained anonymous. The interviews were conducted in both English and Cebuano. Since this paper focused on the statistical analysis and 
measurement of social capital, we used the information collected from these interviews as a qualitative supplement to the quantitative analysis.

\subsubsection{Spatial Autoregressive (SAR) Model}

While ANOVA and a-spatial regressions, including ordinary least squares (OLS), are commonly performed in quantitative assessments and factor analysis, care must be taken when the variables of interest are likely to be spatially correlated, particularly with the dependent variable. The degree of individual-level social capital can depend partly on the geographical distance between holders of differing levels of social capital, as distance can foster relationships and communication [36]. Since the spatial correlation in important variables may lead to bias in estimated coefficients in the estimation [37], we employed the spatial autoregressive (SAR) model to control for such possible bias and, at the same time, to explicitly capture the endogenous social effects of the dependent variable, which reflected social interactions between individuals. Moreover, the explicit incorporation of spatial dependence in the error term enabled us to control for unobservable factors correlated within the community that could affect the outcome, which can be confounded with the actual endogenous spillover effect. Correlated effects, as opposed to endogenous effects, can absorb a possible self-selection bias as well, which is a remarkable advantage of using the SAR model framework.

As the first step, we examined the spatial autocorrelation using the global Moran's I test statistic, based on the OLS residual from the regression of the UG result. Moran's I, expressed as Equation (1), takes a value between -1 and 1 , where a positive (or negative) value indicates positive (or negative) autocorrelation in the dependent variable:

$$
I=\frac{N \sum_{i=1}^{n} \sum_{j=1}^{n} W_{i j}\left(Y_{i}-\bar{Y}\right)\left(Y_{j}-\bar{Y}\right)}{\left(\sum_{i=1}^{n} \sum_{j=1}^{n} W_{i j}\right) \sum_{i=1}^{n}\left(Y_{i}-\bar{Y}\right)^{2}},
$$

where $N$ is the total sample size of participants, $Y_{i}$ and $Y_{j}$ indicate the result of the UG for individuals $I$ and $j$, respectively, $\bar{Y}$ is the UG sample average, and $W_{i j}$ is the $i-j$ element of the weight matrix $W$.

The weight matrix $\left(W_{i j}\right)$ that we utilized is of a distance decay function, which takes into account the effect of spatial interaction diminished by distance. First, the inverse distance is assigned to each element of the weight matrix as in Equation (2):

$$
W_{i j}=\frac{1}{d_{i j}}
$$

where $d_{i j}$ indicates the distance between $i$ and $j$. This function accounts for the common characteristics of nearby individuals' social capital: i.e., increased distance between individuals is expected to weaken their social relationships [36]. The matrix elements are then row-standardized so that the sum of all elements in every row is unified.

If the Moran's I test on spatial autocorrelation is significant, the SAR model must be established. The major choices under the SAR framework are the Spatial Lag Model (SLM), the Spatial Error Model (SEM), and a combination of the two (the ARAR model). Using the weight matrices, the ARAR model is expressed as follows:

$$
\begin{gathered}
Y=\rho W_{1} Y+X \beta+\mu, \\
\mu=\lambda W_{2} \mu+\epsilon,
\end{gathered}
$$

where the first term on the right-hand side of Equation (3) represents the spatial lag effect, while the first term on the right-hand side of Equation (4) accounts for the spatial correlation in unobserved factors. The weight matrices $W_{1}$ and $W_{2}$ can be either the same or different depending on how one defines the spatial process.

When the coefficient $\lambda$ is statistically insignificant, the ARAR Model reduces to the SLM as follows: 


$$
Y=\rho W Y+X \beta+\epsilon,
$$

This is a structural form with the endogenous term on the right-hand side. When rearranging Equation (5) by moving the endogenous term $\rho W Y$, we obtain the reduced form:

$$
Y=(\mathrm{I}-\rho W)^{-1} X \beta+(\mathrm{I}-\rho W)^{-1} \epsilon,
$$

where, in this sequence, the coefficient $(I-\rho W)^{-1}$ indicates that the coefficient $\beta$ is not equal to the marginal effects of $X$ when the coefficient $\rho$ is statistically significant. The coefficient $\rho$ captures the endogenous social effect, which is the mutual influence in $Y$ between the neighboring farmers.

By contrast, when $\rho$ is statistically insignificant instead of $\lambda$, the ARAR model reduces to the SEM as follows:

$$
\begin{gathered}
Y=X \beta+\mu, \\
\mu=\lambda W \mu+\epsilon,
\end{gathered}
$$

When rearranging Equation (7) by moving $\lambda W$ in Equation (8), we obtain the reduced form:

$$
Y=X \beta+(I-\lambda W)^{-1} \epsilon,
$$

To determine the model specification among SLM, SEM, and the ARAR model, we utilize the Lagrange Multiplier (LM) tests for spatial diagnostics, provided that the Moran's I holds significant. If the result of the LM test points to SLM, we do not need to model an autocorrelation in the error term. This means that there are no neighborhood effects arising from unobservable factors, including selection effects.

Since the reduced form equations are not linear in coefficients, SLM, SEM, and the ARAR model are estimated by maximum likelihood estimation (MLE) [38], as the use of least squares regressions would suffer a severe endogeneity bias unless properly treated with valid instrumental variables (IV). A prime example of successful least squares estimation is the two-stage least squares (2SLS) estimation conducted by Bramoullé et al. [39] in which higher-degree neighbors were adopted for identifying instruments of which the validity is assured by the test for necessary and sufficient conditions for identification. Recently, the feat by Bramoulle et al. [39] was followed by Krishnan and Patnam [40], who study farmer-to-farmer technology dissemination in Ethiopia using IV. Another viable method is generalized methods of moments (GMM), which was suggested by Lee [41]. The GMM was further developed by Lin and Lee [42] and Elhorst [43] in their discussion of these various methods' pros and cons.

In analysis, we tried some different combinations of the control variables for robustness of the estimations. To assess the global fit of the models, we consider Akaike Information Criterion (AIC) [44]:

$$
\text { AIC }=-2 \times \log \text { likelihood }+2 \times K,
$$

where $K$ is the number of parameters in the equation. Obviously, the smaller the AIC is, the better the fit becomes.

\section{Results}

\subsection{Ultimatum Game}

The beneficiaries and non-beneficiaries of the irrigation project have clear differentiating results in the UG (Table 3 and Figure 3). The beneficiaries (25.12 PhP) exhibited lower mean threshold values in UG results compared to the non-beneficiaries (34.47 PhP). The difference was supported by the $t$-test $(p<0.001)$. Previous knowledge is that participants from smaller-scale societies exhibit lower values in UG results because they are more inclined to consider tolerance than retaliation or economic 
payoff [45]. Likewise, the irrigated communities (i.e., a TSA of twenty or more farmers) in our study also exhibited pro-social behavior. A more formal estimation was performed by SAR analysis.

Table 3. Results for the Ultimatum Game (UG) experiment and the difference between beneficiaries and non-beneficiaries.

\begin{tabular}{cccc}
\hline Statistic & Beneficiaries & Non-Beneficiaries & $\boldsymbol{t}$-Test | (1) - (2) | \\
\hline Average (Std. Dev) & $25.12(16.47)$ & $34.47(21.29)$ & $9.36 t(212)=3.81, p<0.001$ \\
\hline
\end{tabular}

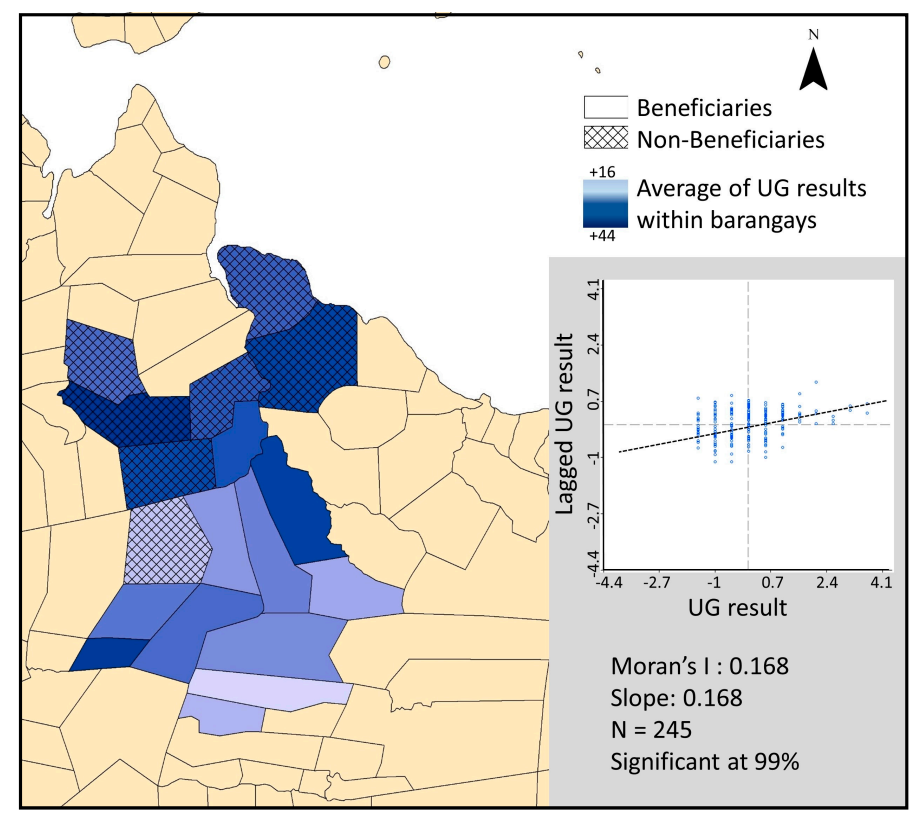

Figure 3. The average values of the ultimatum game (UG) result at Barangay level, and Global Moran's I plot.

The barangay average values of the UG results plotted on the map exhibited the different patterns of UG results across the study area (Figure 3). While the beneficiaries have homogenous patterns of lower UG results, the non-beneficiaries hold heterogeneous patterns of higher UG results.

\subsection{SAR Estimation}

The global Moran's I statistic with the UG results was 0.168 , and its $p$-value was less than 0.001 , which suggested a positive spatial autocorrelation in the level of UG results. The result of the LM tests (90\% significance level) suggested SLM as the appropriate spatial model, meaning that the spatial autocorrelation did not stem from the spatial correlation in unobserved factors. Moreover, our weight matrices passed the test for necessary and sufficient conditions for identification of social effects, proposed by Bramoulle et al. [39], which assures satisfaction of the conditions needed to avoid the reflection problem elaborated upon by Manski [46].

Table 4 presents the results of the SLM estimations. While the OLS model (1) indicates that both irrigation and assets have statistically significant impacts on the UG results, the Moran's I and the LM test imply that further spatial analysis is necessary. Model (2) reveals the statistically significant and positive endogenous spatial effect $(\rho)$ after controlling for individual (i.e., age, gender, and education) and household (i.e., asset holdings, the number of household members, and female ratio) characteristics. Hence, model (2) suggests that the individuals' level of social capital, as measured by the UG receivers' threshold, was linked with the level of social capital of their neighbors. The endogenous spatial effect also implies that the coefficients of the control variables may have suffered bias if spatial models had not been employed. 
Table 4. Results of the Spatial Lag Model (SLM) regressions of the Ultimatum Game (UG) results on the spatial spillover effect and individual/household characteristics. Dependent variable: UG results (receiver's threshold).

\begin{tabular}{|c|c|c|c|c|c|}
\hline Category & Independent Variable & (1) OLS & (2) SLM All & $\begin{array}{c}\text { (3) SLM } \\
\text { Beneficiaries }\end{array}$ & $\begin{array}{c}\text { (4) SLM } \\
\text { Non-Beneficiaries }\end{array}$ \\
\hline \multicolumn{2}{|c|}{ Endogenous spatial effect $(\rho)$} & - & $\begin{array}{l}0.243^{* *} \\
(0.086)\end{array}$ & $\begin{array}{l}0.213 * \\
(0.114)\end{array}$ & $\begin{array}{c}0.122 \\
(0.142)\end{array}$ \\
\hline \multirow{3}{*}{$\begin{array}{c}\text { Individual } \\
\text { characteristics }\end{array}$} & Age & $\begin{array}{c}0.043 \\
(0.109) \\
\end{array}$ & $\begin{array}{c}0.063 \\
(0.105) \\
\end{array}$ & $\begin{array}{c}0.272 * * \\
(0.109)\end{array}$ & $\begin{array}{l}-0.302 \\
(0.194)\end{array}$ \\
\hline & Gender & $\begin{array}{l}1.047 \\
(2.715)\end{array}$ & $\begin{array}{c}0.37 \\
(2.621)\end{array}$ & $\begin{array}{c}4.051 \\
(2.970)\end{array}$ & $\begin{array}{l}-5.181 \\
(4.263)\end{array}$ \\
\hline & Education & $\begin{array}{l}-0.258 \\
(0.449)\end{array}$ & $\begin{array}{l}-0.227 \\
(0.433)\end{array}$ & $\begin{array}{c}0.258 \\
(0.482)\end{array}$ & $\begin{array}{l}-1.066 \\
(0.725)\end{array}$ \\
\hline \multirow{4}{*}{$\begin{array}{l}\text { Household } \\
\text { characteristics }\end{array}$} & Irrigation & $\begin{array}{l}-10.37^{* * *} \\
(2.497)\end{array}$ & $\begin{array}{l}-7.697^{* *} \\
(2.504)\end{array}$ & - & - \\
\hline & Asset holding $(\ln )$ & $\begin{array}{l}-3.152^{* * *} \\
(1.132)\end{array}$ & $\begin{array}{l}-3.066^{* *} \\
(1.093)\end{array}$ & $\begin{array}{l}-5.289 * * \\
(1.116)\end{array}$ & $\begin{array}{l}1.433 \\
(2.032)\end{array}$ \\
\hline & $\begin{array}{c}\text { Number of household } \\
\text { members }\end{array}$ & $\begin{array}{l}-0.073 \\
(0.532)\end{array}$ & $\begin{array}{l}-0.048 \\
(0.514)\end{array}$ & $\begin{array}{l}-0.076 \\
(0.540)\end{array}$ & $\begin{array}{l}-0.566 \\
(0.914)\end{array}$ \\
\hline & Female ratio & $\begin{array}{l}2.199 \\
(7.564)\end{array}$ & $\begin{array}{c}0.97 \\
(7.304)\end{array}$ & $\begin{array}{l}12.225 \\
(8.834)\end{array}$ & $\begin{array}{l}-6.848 \\
(11.284)\end{array}$ \\
\hline Intercept & - & $\begin{array}{l}66.373^{* *} \\
(14.269)\end{array}$ & $\begin{array}{l}56.415^{* *} \\
(14.140)\end{array}$ & $\begin{array}{l}51.235^{* *} \\
(15.087)\end{array}$ & $\begin{array}{l}47.949 * * \\
(23.920)\end{array}$ \\
\hline \multirow{2}{*}{ Goodness of fit } & AIC & 2140 & 2135 & 1087 & 1032 \\
\hline & Log likelihood & -1087.9 & -1057.6 & -534.4 & -507.0 \\
\hline
\end{tabular}

Notes: OLS: ordinary least squares. $N=245$ in Model (1) and (2); $N=131$ in Model (3); $N=114$ in Model (4); ${ }^{* * *} p<0.01,{ }^{* *} p<0.05,{ }^{*} p<0.1$. The numbers in parentheses are standard errors.

To scrutinize the differences between the beneficiaries and non-beneficiaries, we divided the sample and built two models: (3) and (4). Comparing the endogenous spatial effect ( $\rho$ ) in models (3) and (4), the results indicate that only the beneficiaries had a spatial spillover effect on the formation of social capital. Given the heterogeneous patterns of the barangay-level UG results in Figure 3 and the absence of a management community (i.e., IA and TSA) in the rainfed area, the lack of endogenous spatial effect is plausible in the rainfed area (non-beneficiaries).

In models (1), (2) and (3), the individual characteristics variables (gender, age, and schooling years), as well as the family size and female ratio did not exhibit statistically significant effects. On the other hand, access to the irrigation system, asset holdings, and neighbors' social capital had significant effects on the UG results on the whole. According to model (2), one unit increase in the neighbors' UG results leads to a 0.243 unit increase in the UG results on average. In relation to our hypothesis, the coefficient of access to the irrigation system is -7.697 , which represents a direct negative effect from irrigation on the indicator of retaliatory behavior. Using the spatial multiplier $(1-\rho)^{-1}=1.321$ for the averaged total effect, the incorporation of the indirect effect through the neighbors' dependent variable resulted in $(1-\rho)^{-1} \beta_{1}=-10.168$. That is, when the non-beneficiaries received the irrigation system, their measured level of retaliatory behavior would decrease by 10.168 units on average, holding the covariates constant. The result clearly suggests that the collective action required in gravity irrigation management enhances pro-social behavior among the beneficiaries. The significant coefficient of asset holdings indicates that a $1 \%$ increase in asset value was associated with a change in the UG results by $(1-\rho)^{-1} \beta_{2}=-4.0502$ units on average. This decrease suggests that wealthier residents tended to act in a more tolerant manner, which is consistent with previous research [11,45]. Even though the beneficiaries possessed lower amounts of assets than the non-beneficiaries (Table 2), which negatively affect the level of social capital, access to the irrigation system compensated for that loss to a large extent. 


\section{Discussion}

\subsection{The Irrigation Scheme and Social Capital}

This study explored the social impact exhibited by access to irrigation in order to provide insight into how local development projects affect social capital. We found lower values in the UG results among the beneficiaries than among the non-beneficiaries, which suggests that the beneficiaries tended to tolerate unequal distribution more than the non-beneficiaries (Tables 3 and 4). The results concluded that the irrigation management scheme (both IA and TSA) played a key role in the development of social capital in the study area. In this behavioral experiment, actual payoff was at stake, in line with the real life incentive structures. Hence, people who have stronger ties within a small-scale society should exhibit greater tolerance in view of the ongoing social obligation $[45,47]$.

Further analysis was conducted with the SAR model to control for the spillover of social capital as well as the unobservable effects within the neighborhood. Negative effects of the irrigation intervention were found on the result of UG (Table 4.), which is equivalent to the positive effects on the levels of tolerating behavior as one form of social capital. Large asset holders also tended to exhibit a higher level of pro-social behavior, suggesting a social capital growth associated with the enhancement of social status. Moreover, we found a spatial spillover effect of social behavior through the estimation of the SAR model: i.e., a close neighbor's social behavior influences that of the individual. The implication of the results is that both high and low levels of social capital spilled over to close neighbors.

\subsection{Irrigation Management Communities and Social Capital}

Since the irrigation organizations (both IA and TSA) were formed based on their geographical location, the required collective management in the irrigation scheme likely induced the formation of social capital within the TSA and IA. Therefore, the suggested impact of the local development scheme can be further understood by recognizing the social interactions necessitated among the beneficiaries. Comparison of the endogenous spatial effect $(\rho)$ between models (3) and (4) (Table 4.) substantiated this situation as well, as rainfed farmers (non-beneficiaries) did not have a spillover effect on the UG results. This implies that social capital was influenced by an active participation in community practices (i.e., with irrigation organizations in this study). The newly structured agricultural communities (IA and TSA) were unique and had not existed in the region before. This change was vital to improving the beneficiaries' sense of belonging to the community in comparison to the non-beneficiaries who were not involved in the irrigation project.

Furthermore, as Kuper et al. [48] stated, participation in and contribution to community-level activities are crucial in development procedures that require semi-autonomous management. The TSA structure allows us to deduce implications in this regard. According to our qualitative interviews with the respondents, through collective management processes, individual farmers voluntarily repaired sub-lateral canals and grouped themselves together to purchase agricultural machinery and offer a micro-credit scheme for mutual help within the community. Simultaneously, the NIA reimbursed 50\% of canal maintenance costs to TSA members, which was utilized as a fund to implement community activities. The TSA structure has triggered community activity never seen before. Community involvement-in this case, water governance-enhanced the effective and concerted use of the community's limited common resources [14,49-51].

\subsection{Irrigation Project and Agrarian Future}

During the field interviews, we identified a larger sense of community among the beneficiaries than among the non-beneficiaries. The interviewees commonly mentioned "future of our neighborhoods" and their common goals for upcoming cultivation periods. Although we cannot fully prove these facts with the limitation in time-series data, we could emphasize the power of social capital accumulation within communities. Likewise, as Putnam [6] states, a deep bond within a community can foster regional economic success. Since the majority of the residents in our study site had yet to 
secure a stable income, the irrigation scheme, as well as the civic engagement within the restructured communities, are expected to improve stability in agricultural production and make a remarkable difference in the residents' welfare.

Another vital observation is that farmers employed in the irrigation construction process voluntarily laid concrete into the sub-lateral canals and used their existing construction knowledge. Those with skills in advanced technology freely shared this knowledge with fellow farmers. In addition, this success story encouraged farmers to adopt innovative technology. Various farmers in the beneficiaries' area have been designated as model farmers under the Department of Agriculture (DA) program in their production of hybrid rice, which contributed to the improvement in agricultural productivity within a short period. During an interview, the leader of TSA 14 reported "I am quite optimistic about the future of Bohol agriculture and also want my three sons, who are studying crop science, veterinary, and agronomy in colleges, to stay and work in Bohol"'. This brief statement symbolizes the positive outlook and attitude of having a career as a farmer when given access to the irrigation system.

\subsection{Limitation}

Three main limitations exist in our study. First, our UG results cannot be over-generalized. Since UG results can vary depending on the local and regional contexts, it requires discretion to directly apply our finding to other sites. Thus, we limited the interpretation of the UG results to a small-scale society, where reputation is considered important relative to their economic reward. It must be noted, however, that the UG results can be interpreted differently, where a high level of retaliatory behavior may be evidence of social norms and fairness that support cooperation. Hence, careful consideration must be exercised when applying our results into another context. Second, as DeFilippis [52] argued, there is some limitation in measurements of social capital through behavioral experiments. Artefactual experiments typically rely on monetary values as units of measurement, which implies that the result could be influenced by unobservable individual characteristics associated with monetary management or the ability to conduct arithmetic. Third, this study employed an unplanned consequential experiment, where beneficiaries and non-beneficiaries were randomly selected within a certain range of the project site. This means that we can assume that the two groups shared similar socio-economic and cultural characteristics prior to the experiment. In principle, however, it would have been ideal if there had been a baseline study in advance of the intervention, so that we could utilize the Difference-in-Difference (DID) type of estimator to explicitly control for the ex-ante status of social capital. In this respect, we admit that this study is not conducive to a formal assessment of the impact of the treatment (i.e., irrigation scheme) on the outcome (i.e., social capital). In summary, our findings rely on the three items: (1) the interpretation of tolerance that corresponds to small-scale societies formulated by collective irrigation management; (2) the fact that the intervention was conducted in a non-selective, way as noted in the introduction; and (3) the spatial econometric framework that can account for a possible selection bias resulting from spatial correlation of unobservable factors.

\section{Conclusions}

We summarize our conclusion as follows: (1) local development projects with agricultural community engagement can not only enhance agricultural productivity but also social relationships among the beneficiary farmers; (2) these enhanced social relationships and accumulated social capitals are vital mechanisms that give rise to enhanced pro-social behavior among farmers; and (3) local development projects with civic engagement may strengthen management and cooperation by involving stakeholders as key players in the projects-which fosters agricultural productivity and social capital simultaneously.

These points can be significantly applied to local development projects in the global south, which have implemented economic development plans through agricultural infrastructure (e.g., irrigation scheme). 
Since many of these projects were planned by the central government and multinational agencies, maintenance issues followed after management roles were transferred to the local government [53]. Civic engagement, however, involves local stakeholders as key players in local development projects and offers a plausible solution when the local government is incapable of adequate project maintenance. While further specifications for policy development are needed, we tentatively conclude that civic engagement-a platform for accumulating social capital and developing pro-social behaviors—is key to successful local development projects.

Acknowledgments: The authors are grateful to the Social Sciences Division of the International Rice Research Institute (IRRI) that financed this study through the GRiSP (Global Rice Science Partnership) funding. Japan International Cooperation Agency (JICA) supported the Bayongan irrigation project. Japan International Research Center for Agricultural Sciences (JIRCAS) funded the data collection. We also thank the Foundation of Agri-Tech Commercialization and Transfer (FACT) for a research fellowship, which supported the first author's research internship in IRRI. Graduate School of Environmental Studies, Seoul National University provided the fees for editing and open access publication. Samarendu Mohanty encouraged the authors to implement the research. Kei Kajisa and Keitaro Aoyagi were instrumental in the data collection process. Edmund Mendez contributed to the local resource mobilization. Lastly, the authors are thankful to the farmer respondents in Bohol who kindly participated in this study.

Author Contributions: Hogeun Park analyzed the data, led in drafting the manuscript, and selected the journal; Takuji W. Tsusaka supervised the entire process, provided the processed data, and revised the manuscript; Valerien O. Pede contributed the spatial econometrics methodology and analytical expertise; Kyung-Min Kim structured the manuscript and contributed the model interpretation.

Conflicts of Interest: The authors declare no conflict of interest.

\section{References}

1. Development Assistance Committee. Is it ODA? The Organisation for Economic Co-operation and Development (OECD): Paris, France, 2008.

2. Dethier, J.-J.; Effenberger, A. Agriculture and development: A brief review of the literature. Econ. Syst. 2012, 36, 175-205. [CrossRef]

3. Anríquez, G.; Stamoulis, K. Rural development and poverty reduction: Is agriculture still the key. J. Agric. Dev. Econ. 2007, 4, 5-46.

4. Weber, M.; Krogman, N.; Antoniuk, T. Cumulative effects assessment: Linking social, ecological, and governance dimensions. Ecol. Soc. 2012, 17, 22. [CrossRef]

5. Korten, D.C. Community organization and rural development: A learning process approach. Public Adm. Rev. 1980, 480-511. [CrossRef]

6. Putnam, R. The prosperous community: Social capital and public life. Am. Prospect 1993, 4, 35-42.

7. Coleman, J.S. Foundations of Social Theory; Harvard University Press: Cambridge, MA, USA, 1990.

8. Harriss, J.; de Renzio, P. Policy arena: 'Missing link'or analytically missing? The concept of social capital. J. Int. Dev. 1997, 9, 919-937. [CrossRef]

9. Ostrom, E. Collective action and the evolution of social norms. J. Econ. Perspect. 2000, 14, 137-158. [CrossRef]

10. Bowles, S.; Gintis, H. Social capital and community governance. Econ. J. 2002, 112, 419-436. [CrossRef]

11. Hayami, Y. Social capital, human capital and the community mechanism: Toward a conceptual framework for economists. J. Dev. Stud. 2009, 45, 96-123. [CrossRef]

12. Baud, I.S.A.; Pfeffer, K.; Sridharan, N.; Nainan, N. Matching deprivation mapping to urban governance in three Indian mega-cities. Habitat Int. 2009, 33, 365-377. [CrossRef]

13. Mitra, A. Social capital, livelihood and upward mobility. Habitat Int. 2008, 32, 261-269. [CrossRef]

14. Acey, C. Neighbourhood effects and household responses to water supply problems in nigerian cities. TD J. Transdiscip. Res. S. Afr. 2008, 4, 123-156. [CrossRef]

15. Tukahirwa, J.T.; Mol, A.P.J.; Oosterveer, P. Access of urban poor to NGO/CBO-supplied sanitation and solid waste services in Uganda: The role of social proximity. Habitat Int. 2011, 35, 582-591. [CrossRef]

16. Michelini, J.J. Small farmers and social capital in development projects: Lessons from failures in Argentina's rural periphery. J. Rural Stud. 2013, 30, 99-109. [CrossRef]

17. Uphoff, N.; Wijayaratna, C.M. Demonstrated benefits from social capital: The productivity of farmer organizations in Gal Oya, Sri Lanka. World Dev. 2000, 28, 1875-1890. [CrossRef] 
18. Tsusaka, T.W.; Kajisa, K.; Pede, V.O.; Aoyagi, K. Neighborhood effects and social behavior: The case of irrigated and rainfed farmers in Bohol, the Philippines. J. Econ. Behav. Organ. 2015, 118, 227-246. [CrossRef]

19. Lam, W.F. Institutional design of public agencies and coproduction: A study of irrigation associations in Taiwan. World Dev. 1996, 24, 1039-1054. [CrossRef]

20. Ostrom, E. Design principles in long-enduring irrigation institutions. Water Resour. Res. 1993, 29, $1907-1912$. [CrossRef]

21. Uphoff, N. Grassroots organizations and ngos in rural development: Opportunities with diminishing states and expanding markets. World Dev. 1993, 21, 607-622. [CrossRef]

22. Kolm, S.-C. Introduction: The economics of reciprocity, giving and altruism. In The Economics of Reciprocity, Giving, and Altruism; Gerad-Varet, L.-A., Kolm, S.-C., Ythier, J.M., Eds.; Macmillan Press: Basingstoke, UK, 2000; Volume 130, pp. 1-46.

23. Meidinger, C. Equity, fairness equilibria and coordination in the ultimatum game. In The Economics of Reciprocity, Giving, and Altruism; Gerad-Varet, L.-A., Kolm, S.-C., Ythier, J.M., Eds.; Macmillan Press: Basingstoke, UK, 2000; Volume 130, pp. 142-152.

24. Fehr, E.; Simon, G. Fairness and retaliation: The economics of reciprocity. J. Econ. Perspect. 2000, 14, $159-181$. [CrossRef]

25. Fehr, E.; Kirchsteiger, G.; Riedl, A. Does fairness prevent market clearing? An experimental investigation. Q. J. Econ. 1993, 437-459. [CrossRef]

26. Berg, J.; Dickhaut, J.; McCabe, K. Trust, reciprocity, and social history. Games Econ. Behav. 1995, 10, $122-142$. [CrossRef]

27. Hoffman, E.; McCabe, K.; Smith, V.L. Social distance and other-regarding behavior in dictator games. Am. Econ. Rev. 1996, 86, 653-660.

28. Abbink, K.; Irlenbusch, B.; Renner, E. The moonlighting game: An experimental study on reciprocity and retribution. J. Econ. Behav. Organ. 2000, 42, 265-277. [CrossRef]

29. Gintis, H.; Bowles, S.; Boyd, R.; Fehr, E. Explaining altruistic behavior in humans. Evolut. Hum. Behav. 2003, 24, 153-172. [CrossRef]

30. Sanfey, A.G.; Rilling, J.K.; Aronson, J.A.; Nystrom, L.E.; Cohen, J.D. The neural basis of economic decision-making in the ultimatum game. Science 2003, 300, 1755-1758. [CrossRef] [PubMed]

31. Carpenter, J.P.; Daniere, A.G.; Takahashi, L.M. Cooperation, trust, and social capital in Southeast Asian urban slums. J. Econ. Behav. Organ. 2004, 55, 533-551. [CrossRef]

32. Carpenter, J. Measuring social capital: Adding field experimental methods to the analytical toolbox. In Social Capital and Economic Development: Well-Being in Developing Countries; Edwar Elgar Publishing: Northampton, MA, USA, 2002; pp. 119-137.

33. Bouma, J.; Bulte, E.; van Soest, D. Trust and cooperation: Social capital and community resource management. J. Environ. Econ. Manag. 2008, 56, 155-166. [CrossRef]

34. Buchan, N.; Croson, R.T.; Johnson, E.J. Trust and Reciprocity: An International Experiment. Available online: http:/ / appropriate-economics.org/materials/trust_and_reciprocity.pdf (accessed on 7 March 2017).

35. Dufwenberg, M.; Muren, A. Generosity, anonymity, gender. J. Econ. Behav. Organ. 2006, 61, 42-49. [CrossRef]

36. Hipp, J.R.; Perrin, A.J. The simultaneous effect of social distance and physical distance on the formation of neighborhood ties. City Community 2009, 8, 5-25. [CrossRef]

37. Anselin, L. Spatial externalities, spatial multipliers, and spatial econometrics. Int. Reg. Sci. Rev. 2003, 26, 153-166. [CrossRef]

38. Ord, K. Estimation methods for models of spatial interaction. J. Am. Stat. Assoc. 1975, 70, 120-126. [CrossRef]

39. Bramoullé, Y.; Djebbari, H.; Fortin, B. Identification of peer effects through social networks. J. Econ. 2009, 150, 41-55. [CrossRef]

40. Krishnan, P.; Patnam, M. Neighbors and extension agents in Ethiopia: Who matters more for technology adoption? Am. J. Agric. Econ. 2014, 96, 308-327. [CrossRef]

41. Lee, L.-F. Gmm and 2SLS estimation of mixed regressive, spatial autoregressive models. J. Econ. 2007, 137, 489-514. [CrossRef]

42. Lin, X.; Lee, L.-F. Gmm estimation of spatial autoregressive models with unknown heteroskedasticity. J. Econ. 2010, 157, 34-52. [CrossRef]

43. Elhorst, J.P. Applied spatial econometrics: Raising the bar. Spat. Econ. Anal. 2010, 5, 9-28. [CrossRef] 
44. Akaike, H. Akaike's information criterion. In International Encyclopedia of Statistical Science; Springer: Berlin/Heidelberg, Germany, 2011; p. 25.

45. Henrich, J.; Boyd, R.; Bowles, S.; Camerer, C.; Fehr, E.; Gintis, H.; McElreath, R.; Alvard, M.; Barr, A.; Ensminger, J.; et al. "Economic man" in cross-cultural perspective: Behavioral experiments in 15 small-scale societies. Behav. Brain Sci. 2005, 28, 795-815. [CrossRef] [PubMed]

46. Manski, C.F. Identification of endogenous social effects: The reflection problem. Rev. Econ. Stud. 1993, 60, 531-542. [CrossRef]

47. Marlowe, F.W.; Berbesque, J.C.; Barr, A.; Barrett, C.; Bolyanatz, A.; Cardenas, J.C.; Ensminger, J.; Gurven, M.; Gwako, E.; Henrich, J.; et al. More 'altruistic' punishment in larger societies. Proc. R. Soc. B Biol. Sci. 2008, 275, 587-592. [CrossRef] [PubMed]

48. Kuper, M.; Dionnet, M.; Hammani, A.; Bekkar, Y.; Garin, P.; Bluemling, B. Supporting the shift from state water to community water: Lessons from a social learning approach to designing joint irrigation projects in Morocco. Ecol. Soc. 2009, 14, 19. [CrossRef]

49. Cifdaloz, O.; Regmi, A.; Anderies, J.M.; Rodriguez, A.A. Robustness, vulnerability, and adaptive capacity in small-scale social-ecological systems: The pumpa irrigation system in nepal. Ecol. Soc. 2010, 15, 39. [CrossRef]

50. Schulz, C.; Martin-Ortega, J.; Glenk, K.; Ioris, A.A.R. The value base of water governance: A multi-disciplinary perspective. Ecol. Econ. 2017, 131, 241-249. [CrossRef]

51. Ballester, A.; Mott Lacroix, K. Public participation in water planning in the Ebro river basin (Spain) and Tucson basin (U.S., Arizona): Impact on water policy and adaptive capacity building. Water 2016, 8, 273. [CrossRef]

52. DeFilippis, J. The myth of social capital in community development. Hous. Policy Debate 2001, 12, 781-806. [CrossRef]

53. Mukherji, A.; Fuleki, B.; Shah, T.; Suhardiman, D.; Giordano, M.; Weligamage, P. Irrigation Reform in Asia: A Review of 108 Cases of Irrigation Management Transfer; International Water Management Institute: Colombo, Sri Lanka, 2009.

2017 by the authors. Licensee MDPI, Basel, Switzerland. This article is an open access article distributed under the terms and conditions of the Creative Commons Attribution (CC BY) license (http:/ / creativecommons.org/licenses/by/4.0/). 